\title{
Evaluation System for Implicit Ideology \& Political Education in Applied Universities Based on SEM*
}

\author{
Xiaoli $\mathrm{Lu}^{1}$ \\ Zhejiang Pharmaceutical College
}

\author{
Shanhui Wang ${ }^{2}$ \\ Ningbo Institute of technology
}

\begin{abstract}
The recessive ideological and political (I\&P) education system in applied universities consists of such four components as knowledge, environment, activities and occupation. It is supposed that the system composed of these four components has positive effects on I\&P level of students in applied universities. Then, a SEM model is used to analyze and verify the hidden factors that affect I\&P level of these students. The findings show that the knowledge, occupation, activity and environment levels all play a positive effect on students' I\&P level to a sequentially progressive extent. In the end, it is suggested that applied universities should take some effective measures to foster high-quality talents, Measures that involve the intensification of the educational environment construction, the enrichment of campus life, and the improvement of students' professional literacy should be taken so as to stimulate the recessive I\&P education to exert more positive role in this regard.
\end{abstract}

\section{Keywords}

SEM (Structural Equation Method) • Implicit I\&P Education • Evaluation

\footnotetext{
* This paper is supported by Zhejiang Province philosophy society planning and ideological and political issues (No. 16GXSZ015YB), Key Scientific Research Projects of Zhejiang Applied University Party Building Research Association and Zhejiang University Ideological and Political Education Research Association (No. 16GXSZ015YB), and the project of famous teaching studio of Ideological and political theory course in Colleges and universities of Zhejiang Province.

${ }^{1}$ Zhejiang Pharmaceutical College, Zhejiang Ningbo 315100, China. Email: 876656949@qq.com

${ }^{2}$ Correspondence to: Ningbo Institute of technology, Zhejiang University, Zhejiang Ningbo 315100, China. Email: wangshanhui323@163.com
} 
The important way to construct the I\&P education system in colleges and universities is people-oriented curriculum education. The 19th National Congress of the Communist Party of China made the strategic position of students' I\&P education and the mission of the university for rearing people more explicit. In the new era, under the influence of new economic development model and humanistic environment, post-2000s-generation students are developing or have developed into characters with the distinct sense of independence, self-reliance, and self-responsibility. However, when compared with those undergraduate students from elite universities, they have only laid a relatively feeble foundation for knowledge as well as the uneven quality. There are also some disparities among them, such as learning habits and motivation, humanities literacy and so on. when instilled the abstract I\&P theories, they are more willing to involve in vivid activities. For a long time, the traditional I\&P education in applied universities has been characterized by explicitness and directness, meanwhile, it is also considered to be too concentrated, monotonous, out of date, and ineffective in moral function. Implicit I\&P education can create a favorable environment and models different from explicit education. It gets rid of rigid education models, imparts students with events, moves people with cares, and enlightens people with fine models. To be hidden but influential, it is an indirect and euphemistic teaching process (Bai, 2013). However, in essence, the implicit I\&P education is such a process in which the cognition is practiced, especially in applied universities. In the design of teaching programs, implicit I\&P education does not use explicit teaching means to support students. it is also difficult to test the emotional experience and affective commitment with the assessment process; in practice, the degree of roles that various types of hidden resources play in the I\&P education level is hard to judge. For this purpose, this paper clarifies the functions of various types of hidden resources on students' I\&P education based on the components of the recessive I\&P education in applied universities, thus to achieve the effective construction for the implicit I\&P education evaluation system in applied universities.

\section{Composition elements of implicit I\&P education in applied universities}

Applied universities are committed to cultivating compound talents as their ultimate objectives. In education model, they have their own distinctive features from ordinary universities. From the angle of the university level, first, applied universities often have occupational features in the majors. They determine the occupationbased training objectives and develop feasible teaching programs in accordance with the knowledge structures required by occupational groups, considering their demands in the long run. Second, the applied universities have practical characteristics and focus on the practices combined with theories. Basically, the knowledge learned in practices in all major's accounts for more than 50\%, and for some engineering majors, the learning hours in practices have even reached $60 \%$. During the teaching process, they focus on developing students' hands-on skills to solve problems occurred in the practical production and works. From the student level, first, the students in applied universities have more obvious personality traits, strong self-awareness, enjoy thinking independently, prefer diverse activities, but sometimes they have a low self-demanding. Second, students in applied universities have a psychology for seeking to be employed in job-hunting process. In the current society, some employers unilaterally pursue high academic qualifications, while there are bias or prejudice against students from applied universities. In this case, students feel a certain inferiority and pressure, while many 
students are eager to learn from multiple ways, quickly master professional skills, gain knowledge valuable to them, and continuously improve the competence to solve problems (Wang, 2012).

Based on the above features, this paper divides the composition of implicit I\&P education in applied universities into the following four elements:

\section{Implicit I\&P education at the knowledge level}

The implicit I\&P education at the knowledge level mainly refers to the teaching contents implied in the teaching process rather than I\&P courses in universities. In the teaching process of specialized courses, in addition to the expertise, such I\&P contents as professional thoughts, occupational ethics, dialectical materialism are also included. Teachers combine these contents into the courses in the education process, to give students a subtle I\&P education. In addition, if universities set up the history and humanity courses, these can not only help advocate the Chinese traditional culture and ideologies, but also have a positive effect on the improvement of students' I\&P level (Kong, 2011).

Hypothesis 1: I\&P education factors implied in the teaching process rather than I\&P curriculum have a positive effect on the development of students' I\&P levels.

\section{Implicit I\&P education at the environment level}

Implicit I\&P education resources at the environmental level include the physical and spiritual worlds. Among them, the former also covers the campus layout, facilities, greening and purification elements, etc. The aesthetics carried in the reasonable architecture layout in campus can make students inspired and infected, and the perfect facilities in campus can help stimulate the development of students' interests. A good greening and purified environment can also inspire students' enthusiasm for life, cultivate the love for nature and life. The spiritual world is more important for the development of students' I\&P moralities. This world contains school spirit, study style, faculty morality, school rules and regulations, etc. School spirit and study style, as the great spiritual strengths, influence students the development of the values and spiritual characters, as well as their professional ethics. Teachers, as educators of expertise, ideologies and morality, have their own moral edification that directly influences the students. In the course and in the process of contact with the students, the teachers are dedicated, noble, and has professional education awareness and professional skills, which all affect students subtly (Lu, 2014). Similarly, in a small society like a university, a reasonable and humanized campus system can guide students to form correct values.

Hypothesis 2: Implicit I\&P education factors at the environmental level have a positive effect on the development of student I\&P levels.

\section{Implicit I\&P education at the activity level}

Implicit I\&P education resources are abundant, and can be found not only in non-hidden courses and environment but also in the activities of students' self-participation and conscious practices. In various activities held in universities, students participate independently and voluntarily, and are tempered with, inspired and developed, so that their autonomy, initiative and creativity are fully exerted. These activities are also divided into two types, i.e. humanistic literacy and campus cultural. The former mainly includes socialist core values, 
gratitude and integrity pedagogies, the essence of traditional Chinese culture, as well as education for occupational etiquette, mental health, social responsibility and the like. There are many forms of activities, such as lectures, essays, debating competitions, speech contests, etc., where students voluntarily involve, enable to make the sense, and profoundly comprehend the various aspects of I\&P character (Ou, Zhou and Zhou, 2011). Campus cultural activities, however, are participated by students most independently, also in the most diverse forms, such as art nurture, cultural and entertainment celebrations, communities, youth volunteers, and online cultural activities. Inspired by these activities in the forms of self-organization, self-participation and selfservice, students not only improve their social and organizational skills but also enhance their sense of social responsibility, practice the humanistic care, exercise their will and perseverance, and accept the I\&P education in practices.

Hypothesis 3: The implicit I\&P education factors at the activity level have a positive effect on the development of student I\&P levels.

\section{Implicit I\&P education at the occupation level}

The training objective of applied universities is to foster high-skilled applied talents. Therefore, in the education process, a large part of the focus is on career-related content, and implicit I\&P education factor at the occupation level plays an important role in the student's I\&P education work. From the perspective of vocational skills, the universities help students to integrate with the enterprises in advance in the learning process by organizing pre-employment activities, vocational situation teaching, professional skill competition, employment skill training and other relevant activities. Universities provide students with career guidance and support, help students develop self-awareness, self-affirmation and self-worth values, while promoting the formation of students' moralities, such as self-confidence and the sense of responsibility. In terms of professionalism, the universities organize the corporate culture experience, entrepreneur forums, career planning counseling, outdoor development and other activities, hence to enable students to establish a good outlook on life and career, cultivate good professional qualities, and improve I\&P levels.

Hypothesis 4: The implicit I\&P education factors at the occupation level have a positive effect on the development of student I\&P levels.

\section{Building model}

Structural Equation Model (SEM) is a statistical analysis method for analyzing the relationship between variables based on the valuable covariance matrix. It is commonly used to process the multiple causalities, and settle the problems with latent variables. With factor and path analysis and by other methods we can verify what degree the theoretical model proposed herein works in concert with data. Based on the SEM, this paper evaluates the implicit I\&P education curriculum in applied universities, and verifies or falsifies the four hypotheses proposed above to measure how the implicit I\&P education curriculum influences the I\&P level of students in 
applied universities, providing the clues to setting up the effective implicit I\&P education curriculums for applied universities.

\section{Selection of indicators and data collection}

Based on the above analysis, this paper believes that there are four levels of hidden factors that influence the development of students' I\&P level in applied universities. At each level, multiple indicators can be used to represent it. This paper designs six measurement indicators for the endogenous variable, I\&P level, and subdivides the four exogenous variables into seven small levels. 39 measurement indicators are available (see Table 1). The questionnaires are further designed with these 45 indicators as the items, each is scored by the Likert 5-point scale. The higher the score, the more they agree with the statement of the item. In this way, each item is measured.

Table 1

Implicit I \& P Education Curriculum Measurement Indicator in Applied University

\begin{tabular}{|c|c|c|c|}
\hline & $\begin{array}{l}\text { Primary } \\
\text { indicators }\end{array}$ & $\begin{array}{l}\text { Secondary } \\
\text { indicators }\end{array}$ & Three-level indicators \\
\hline \multirow{6}{*}{$\begin{array}{l}\text { The } \\
\text { endogenous } \\
\text { variables } \\
\text { (X1) }\end{array}$} & \multirow{6}{*}{$\begin{array}{l}\text { The } \\
\text { ideological \& } \\
\text { political level }\end{array}$} & & $\begin{array}{l}\text { Students have qualified political quality, ideals and beliefs of } \\
\text { socialism and communism (X11) }\end{array}$ \\
\hline & & & $\begin{array}{l}\text { Students have Scientific ideological quality, Scientific world } \\
\text { outlook, Outlook on life, Scientific methodology (X12) }\end{array}$ \\
\hline & & & $\begin{array}{l}\text { Students have good moral quality, the establishment of socialist } \\
\text { moral concept, social ethics, professional ethics and family } \\
\text { virtues (X13) }\end{array}$ \\
\hline & & & $\begin{array}{l}\text { Students have a healthy mental quality, a strong will, modest } \\
\text { and tolerant temperament (X14) }\end{array}$ \\
\hline & & & $\begin{array}{l}\text { Students have comprehensive cultural quality and humanistic } \\
\text { cultivation that can learn new knowledge from Chinese } \\
\text { traditional literature, history and philosophy. There is also a } \\
\text { need for modern scientific knowledge to understand modern } \\
\text { new theories, new technologies, and new materials (X15) }\end{array}$ \\
\hline & & & $\begin{array}{l}\text { Students have the right career view, some professional skills } \\
\text { and strong professional thinking (X16) }\end{array}$ \\
\hline \multirow{7}{*}{$\begin{array}{l}\text { The } \\
\text { exogenous } \\
\text { variables }\end{array}$} & \multirow{2}{*}{$\begin{array}{l}\text { The } \\
\text { knowledge } \\
\text { level (X2) }\end{array}$} & $\begin{array}{l}\text { The specialized } \\
\text { courses }(\mathrm{X} 21)\end{array}$ & $\begin{array}{l}\text { In the teaching of specialized courses, the universities can add } \\
\text { professional thought, dialectical materialism and so on (X21) }\end{array}$ \\
\hline & & $\begin{array}{l}\text { The history and } \\
\text { humanity } \\
\text { courses (X22) }\end{array}$ & $\begin{array}{l}\text { There are history and humanity courses set up in universities, in } \\
\text { order to advocate the Chinese traditional culture and } \\
\text { civilization, and traditional ideologies (X22) }\end{array}$ \\
\hline & \multirow{5}{*}{$\begin{array}{l}\text { The } \\
\text { environment } \\
\text { levels } \\
\text { (X3) }\end{array}$} & \multirow{5}{*}{$\begin{array}{l}\text { The physical } \\
\text { environments } \\
\text { (Y3) }\end{array}$} & $\begin{array}{l}\text { The campus has reasonable and beautiful architecture layout } \\
\text { (X31) }\end{array}$ \\
\hline & & & There are celebrity statues and famous quotes on campus. (X32) \\
\hline & & & $\begin{array}{l}\text { The universities library has abundant collections and complete } \\
\text { data resources (X33) }\end{array}$ \\
\hline & & & $\begin{array}{l}\text { The facilities of practice training, art, sports and other } \\
\text { educational and teaching facilities are perfect (X34) }\end{array}$ \\
\hline & & & $\begin{array}{l}\text { The greening of the campus is good and the sanitary } \\
\text { environment is clean (X35) }\end{array}$ \\
\hline
\end{tabular}


The spiritual

(Y4) environments
The humanistic literacy activities

(Y1)
The universities have an excellent study style, and the students have clear objectives, strong initiative and professional thought (X36)

The teachers are dedicated, noble, and has professional education awareness and professional skills (X37)

The campus has a reasonable and humanized system (X38)

Famous scholars are invited to make reports which are rich and attractive (X39)

The universities hold lectures on socialist core values and comprehensively expounds the core values (X41)

The universities hold lectures or elective courses on the essence of traditional Chinese culture, which fully interpret Chinese culture (X42)

The universities hold activities such as lectures, essay soliciting, debating competitions based on gratitude and integrity pedagogies (X43)

The universities carry out initial education, the content is clear and definite (X44)

The universities concern about students' mental health development, there are set up the mental health counseling rooms, and often carry out mental health lectures, etc. (X45)

The universities pay attention to the cultivation of students' Professional etiquette and other exogenous accomplishments, set up vocational elective courses (X46)

The universities attach importance to the cultivation of students' sense of social responsibility (X47)

The universities conduct occupational safety education through exercises and scenario simulation, etc. (X48)

The universities conduct formal and policy reports to help students have a profound, comprehensive and authentic understanding of forms and policies at home and abroad (X49)

The activity levels

(X4)
The universities pay attention to students' health and health work, especially occupational health, and regularly give lectures on health and health care (X410)

Students understand environmental technology in industry through lectures and other forms (X411)

The universities train students to understand basic legal affairs and regularly conducts lectures on legal matters (X412)

The universities regularly organize campus cultural activities such as voluntary teaching, caring donation and poverty alleviation (X413)

The universities regularly conduct social practice activities, including social surveys, summer surveys, etc. (X414)

The universities regularly hold cultural entertainment celebrations and provide material and financial support for activities. (X415)

The campus The universities encourage the creation of associations and cultural activities provide protection for the construction of associations (X416)

(Y2) The universities organize basketball competitions, sports meetings, speech competitions, top ten singers, and other arts and sports competitions (X417)

The universities develop colorful art activities to enrich students' art feelings (X418)

The universities attach great importance to the establishment of network culture, carrying out network culture festival, network photography competition, network literature competition and other forms of network activities (X419) 


\begin{tabular}{|c|c|c|}
\hline & & $\begin{array}{l}\text { The universities set up special moral education websites, } \\
\text { psychological counseling websites, open school micro-blog } \\
\text { homepages and so on, which enriched the network } \\
\text { communication channels (X420) }\end{array}$ \\
\hline & & $\begin{array}{l}\text { The universities attach great importance to the integrity of } \\
\text { students' organizational construction and the effectiveness of } \\
\text { implementation. (X421) }\end{array}$ \\
\hline \multirow{9}{*}{$\begin{array}{c}\text { The } \\
\text { occupation } \\
\text { level } \\
\text { (X5) }\end{array}$} & \multirow{5}{*}{$\begin{array}{l}\text { Professional } \\
\text { skills } \\
\text { (Y5) }\end{array}$} & $\begin{array}{l}\text { The universities attach importance to the integration of students } \\
\text { and enterprises through organizing pre-employment activities, } \\
\text { vocational situational teaching and so on. (X51) }\end{array}$ \\
\hline & & $\begin{array}{l}\text { The universities pay attention to the promotion and cultivation } \\
\text { of students' professional skills, and improve students' } \\
\text { professional technical level through the training of enterprise } \\
\text { technical experts and employment skills. (X52) }\end{array}$ \\
\hline & & $\begin{array}{l}\text { The universities organize professional skills competitions to } \\
\text { cultivate students' professional skills and enterprising spirit. } \\
\text { (X53) }\end{array}$ \\
\hline & & $\begin{array}{l}\text { The universities make the students understand the current status } \\
\text { of the industry in the form of industry technical report (X54) }\end{array}$ \\
\hline & & $\begin{array}{l}\text { The universities encourage students to start their own } \\
\text { businesses and provide them with innovative funding and } \\
\text { technical support (X55) }\end{array}$ \\
\hline & \multirow{4}{*}{$\begin{array}{l}\text { Professionalism } \\
\text { (Y6) }\end{array}$} & $\begin{array}{l}\text { The universities pay attention to the cultivation of students' } \\
\text { professionalism, and organizes activities such as experience } \\
\text { corporate culture, entrepreneur forum and so on (X56) }\end{array}$ \\
\hline & & Providing guidance for career planning (X57) \\
\hline & & $\begin{array}{l}\text { The universities attach great importance to the cultivation of } \\
\text { students' strong will, self-confidence and unity of professional } \\
\text { qualities, through the organization of outdoor development } \\
\text { activities (X58) }\end{array}$ \\
\hline & & $\begin{array}{l}\text { The universities focus on building student spirit models and } \\
\text { organizing outstanding graduates' reports (X59) }\end{array}$ \\
\hline
\end{tabular}

As this paper studies the implicit I\&P education in applied universities, the questionnaires should be distributed among students in 6 applied colleges and universities, i.e. Zhejiang Medical and Pharmaceutical College, Zhejiang University, Ningbo Institute of Science and Technology, Ningbo Institute of Technology, Zhejiang Wanli University, Ningbo Vocational and Technical College. Among 346 questionnaires distributed, 318 are collected, of which 304 are valid. The recovery rate is $87.86 \%$.

\section{Reliability test}

As a commonly used reliability test method, Cronbach's alpha value is used to measure the reliability of the questionnaire survey. It is generally believed that the Cronbach's $\alpha$ is less than 0.35 , representing a low confidence, and the questionnaire should be rejected; but it is acceptable at above 0.5 or 0.6 of Cronbach's $\alpha$, and highly confident between 0.7 and 0.98 . In this paper, SPSS19.0 is used to test the overall reliability of the whole 304 questionnaires. Its reliability coefficient Cronbach's $\alpha$ is 0.892 , which indicates that the questionnaires have a high degree of reliability. The results from statistical analysis based on the questionnaires are more reliable. 


\section{Model construction and data fitting}

Model construction. This paper uses AMOS 17.0 to test the implicit I\&P education curriculum system model. The observation equation describes the relationship between explicit and latent variables. The measurement model is:

$$
\begin{aligned}
& y=\wedge_{y} \eta+\varepsilon \\
& x=\wedge_{x} \xi+\delta
\end{aligned}
$$

Structural equation:

$$
\eta=\lambda \eta+\Gamma \xi+\zeta
$$

Where equation (1) is the measurement equation of the endogenous latent variable; $y$ is a $\mathrm{p}^{*} 1$ vector composed of $p$ endogenous indicators; $\eta$ is a $\mathrm{m}^{*} 1$ vector composed of $m$ endogenous latent variables; $\wedge_{y}$ is $\mathrm{p}^{*} \mathrm{~m}$ factor load matrix of $\mathrm{y}$ on $\eta ; \varepsilon$ is a $\mathrm{p}^{*} 1$ vector composed of $p$ measurement errors. Equation (2) is the measurement equation of the exogenous variable, where, $\mathrm{x}$ is the $\mathrm{q}^{*} 1$ vector composed of $q$ exogenous indicators; $\xi$ is a $\mathrm{n}^{*} 1$ vector composed of $n$ exogenous indicators; $\wedge_{x}$ is the $\mathrm{q}^{*} \mathrm{n}$ factor load matrix of $x$ on $\xi$; $\delta$ is a $\mathrm{q}^{*} 1$ vector composed of $q$ measurement errors. In equation (3), $\lambda$ is the $\mathrm{m}^{*} \mathrm{~m}$ coefficient matrix, which describes the interaction between endogenous latent variables $\eta ; \Gamma$ is the $\mathrm{m} * \mathrm{n}$ coefficient matrix, which describes the effect of exogenous latent variables $\xi$ on endogenous latent variables $\eta ; \zeta$ is the $\mathrm{m}^{*} 1$ residual variable.

Model fitting. The main fitting effects of this paper are given as follows:

Table 2

The Fitting Effect of the Implicit I \& P Education Curriculum System Model

\begin{tabular}{llccccccc}
\hline Index & CMIN & DF & P & RMR & GFI & NNFI & CFI & RMSEA \\
\hline Value & 1791.8 & 1031 & 0.000 & 0.0436 & 0.894 & 0.902 & 0.914 & 0.0616 \\
\hline
\end{tabular}

It is generally believed that the ratio of the chi-square value to the degree of freedom (CMIN/DF) falls within $1 \sim 2$, while it is 1.74 in this paper. The lower the RMR (root mean square residual), the better it is. The value in this paper is less than 0.1. RMSEA is the root mean square of the approximate error, lower than 0.1 , which implies that the model fits well. Here is 0.894 . The closer the GFI (goodness of fit indicator), NNFI (nonstandardized), CFI (comparative fit indicator) are to 1 , the better these indicators in this paper are around 0.9 . As described above, the model fit better.

\section{Conclusion and comments}

This paper examines the implicit I\&P education curriculum of applied universities via AMOS 17.0. The results from the calculation, as shown in Fig. 1, show that the four hidden factors set herein, namely knowledge, 
environment, activities and occupation, have positive effect on I\&P education level of students in applied universities, so that the four hypotheses as mentioned above are well verified.

From the results, the coefficient at the X3 environmental level is 0.75 , which shows that among the hidden factors at the four levels, the environmental factors have the greatest influence on students' I\&P level, including the physical and spiritual environments. Therefore, to strengthen the I\&P education work, applied universities should first bear the brunt of environmental construction, on the one hand, strengthen afforesting and purification, and create aesthetic influence on students; on the other hand, improve library collections, laboratory equipment and other hardware facilities, in order to provide a material basis for the cultivation of students' interests; of course, what matters more is to enhance construction of good ethos and study style in universities, so that students are tainted in a good spiritual environment to form correct values.

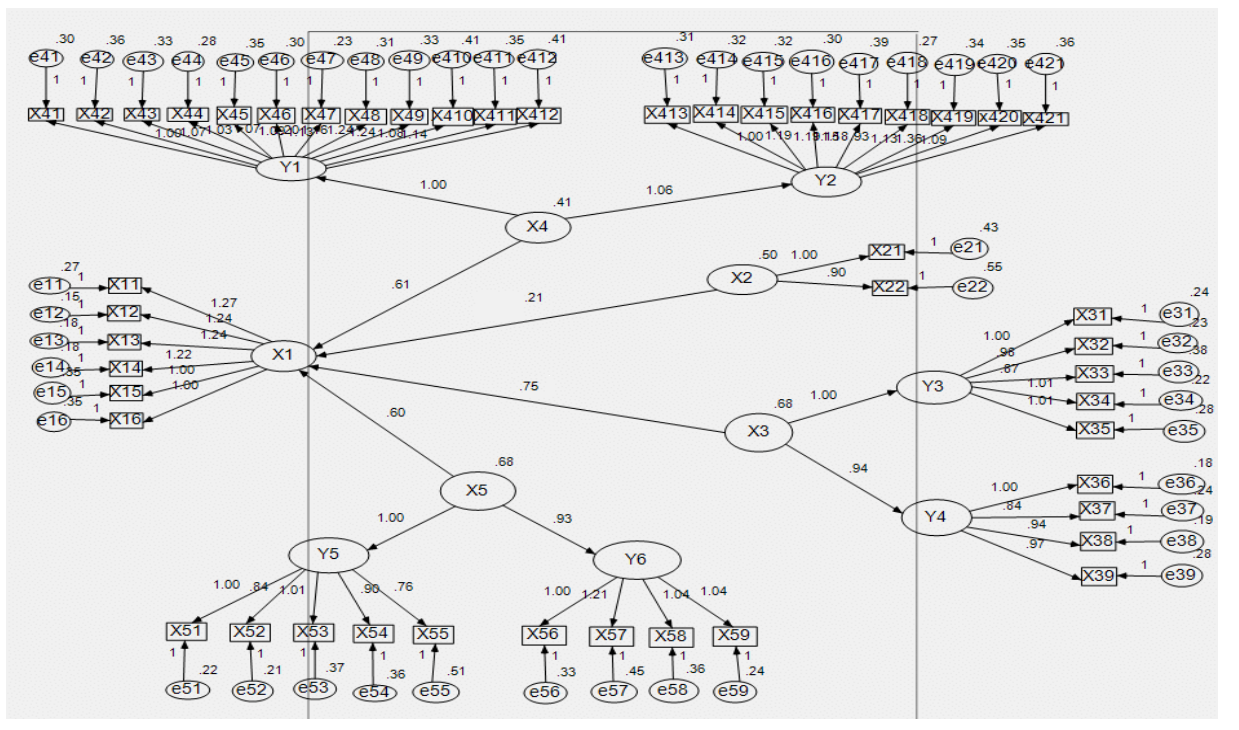

Figure 1. Structural model path and its results from analysis

Next, at the X4 activity and the X5 vocation levels, the I\&P level of students in applied universities matches up, namely 0.6 and 0.61 , respectively, which suggests that campus activities and job training play an important role in improving the I\&P level of students in applied universities. As for the activity level, the rich campus activities trigger the students' interest in learning and life. Students not only practice their own skills in a comprehensive way but also interact and inspire each other to improve themselves at an ideological level when participating in the campus activities. Therefore, it is apparently necessary to carry out a variety of campus activities to improve the student's I\&P level. For applied universities that target at cultivating high-skilled applied talents, professionalism and right outlook are important manifestations of I\&P level. The cultivation of vocational skills plays a pivotal role in improving students' self-awareness, self-confidence, in order to build up a correct outlook on professionalism and vocational ethics by enhancing the cultivation of professional skills and professionalism. 
In the end, the hidden curriculum factor at the X2 knowledge level also has a positive effect on the student's I\&P level, but its coefficient is only 0.21 . It is clear that the impact level is relatively limited. This paper believes that it is attributed to the fact that in the educational environment of applied universities, the cultivation of vocational skills has been placed in the most important position, and some curricula such as history humanities have not been heeded, which explains their weaker effect on students' I\&P in applied universities, but is always positive. In this sense, the construction of hidden I\&P curriculum at the knowledge level cannot be ignored.

\section{References}

Bai, X. L. (2013). Research on the basic theory of recessive ideological and political education. People's Publishing House.

Hendry, G. D., \& Dean, S. J. (2002). Accountability, Evaluation of Teaching and Expertise in Higher Education. International Journal for Academic Development, 7, 75-82. http://dx.doi.org/10.1080/13601440210156493

Kong, L. J. (2011). Reflections on the construction of hidden curriculum in Applied Universities. Research of Education and Teaching. (4), 12-14.

Lagrosen, S., Seyyed-Hashemi, R., \& Leitner, M. (2004). Examination of the dimensions of quality in higher education. quality assurance in education, 12, 61-69. http://dx.doi.org/10.1108/09684880410536431

Liang, B. (2013). Research on Ideological and Political Education in Universities Based on SWOT Analysis Technology. In Proceedings of the International Conference on Information Engineering and Applications (IEA) 2012 (pp. 253-260). Springer, London. https://dx.doi.org/10.1007/978-1-4471-4847-0_31.

Lu, X. L. (2014). Research on the construction of implicit ideological and political education system in Applied Universities. Vocational Education Forum. (29), 41-45

Mao, C. S. (2012). Research on talent cultivation mechanism of the higher vocational education based on industry cluster groups. Research in Education Development. 32(7), 53-57.

Ou, Y. L., Zhou, S. Y. \& Zhou, Q. Q. (2011). Discussion on the development and implementation of hidden curriculum in Applied Universities. Electric Power Education in China, (34), 75-80.

Su Z. F. (2006). Ideological and Political Education. Social Sciences Literature Press.

Wang, H. M. (2012). Thoughts on improving the ideological and moral quality of higher vocational students by hidden curriculum. Journal of Hubei Polytechnic Institute. 15(2), 38-40.

Zhang, Y. (2015) Study on implicit ideological and political education theory and reform in higher vocational colleges. Open Journal of Philosophy, 5, 297-301. http://dx.doi: 10.4236/ojpp.2015.55037. 